\title{
O USO DE AUDIOVISUAIS PROBLEMATIZADORES NO PROCESSO DE INVESTIGAC̣ÃO TEMÁTICA COMO MEIO PARA OBTENC̣ÃO DO TEMA GERADOR
}

\author{
WÉLICA PATRÍCIA SOUZA DE FREITAS * \\ https://orcid.org/0000-0001-6444-4063 \\ WELLINGTON PEREIRA DE QUEIRÓS" ** \\ https://orcid.org/0000-0002-9734-7136
}

RESUMO: O presente artigo apresenta uma análise do processo de Investigação Temática, resultado de uma intervenção didática com abordagem das inter-relações Ciência-TecnologiaSociedade (CTS) realizada com alunos do curso de licenciatura em Física em uma disciplina de prática de Ensino de Física. O processo de Investigação baseou-se em algumas ações, dentre elas a discussão inicial e apresentação de documentários com caráter problematizador das inter-relações CTS. Nas discussões dos documentários, notou-se uma potencialidade para realizar diálogos balizados pela perspectiva Freire-CTS, o que acarretou a elaboração de questionamentos, uma vez que se acredita que esta apresentação se torna um possível subsídio para professores que queiram discutir questões relacionadas à perspectiva Freire-CTS em suas aulas. Os audiovisuais problematizadores descritos caracterizam-se como um meio para potencializar a reflexão e senso crítico nos sujeitos, a fim de analisar e questionar a realidade em que estão inseridos. Este artigo busca apresentar os audiovisuais abordados, bem como as compreensões e resultados tecidos na abordagem dos artefatos problematizadores no processo de Investigação Temática com os estudantes do curso de licenciatura em Física. As ações realizadas (discussão inicial e apresentação dos audiovisuais problematizadores) culminaram para estabelecimento do tema gerador, energia e CTS, que foram analisadas via ATD. $\mathrm{Da}$ análise, emergiram duas categorias finais intituladas " $A$ abordagem de audiovisuais problematizadores como meio para discussão de valores sociais" e "Necessidades formativas desveladas a partir da discussão de documentários problematizadores". O processo de análise desvelou as potencialidades dos audiovisuais para discussões Freire-CTS e a obtenção de temas geradores.

Palavras-chave: Audiovisuais problematizadores. Freire-CTS. Formação Inicial de Professores de Física.

\footnotetext{
${ }^{*}$ Mestre em Ensino de Ciências e doutoranda em Ensino de Ciências pelo Programa de Pós-Graduação em Ensino de Ciências da Universidade Federal de Mato Grosso do Sul (UFMS). E-mail: welicapsf@gmail.com

**Doutor em Educação para a Ciência e Docente do Instituto de Física e do Programa de Pós-Graduação em Ensino de Ciências da Universidade Federal de Mato Grosso do Sul UFMS). E-mail: wellington_fis@yahoo.com.br
}

\footnotetext{
' Universidade Federal de Mato Grosso do Sul, Programa de Pós-Graduação em Ensino de Ciências, Pioneiros, MS - Brasil.

" Universidade Federal de Mato Grosso do Sul, Instituto de Física, Pioneiros, MS - Brasil.
} 


\section{EL USO DE AUDIOVISUALES PROBLEMATIZADORES EN EL PROCESO DE INVESTIGACIÓN TEMÁTICA COMO MEDIO PARA LA OBTENCIÓN DEL TEMA GENERADOR \\ RESUMEN: Este artículo presenta un análisis del proceso de Investigación Temática, resultado} de una investigación didáctica con enfoque de las interrelaciones Ciencia-Tecnología-Sociedad (CTS) llevada a cabo con estudiantes de la Formación Docente en Física en una asignatura de práctica de Enseñanza de Física. El proceso de Investigación se basó en algunas acciones, entre las cuales están la discusión inicial y presentación de documentales con carácter problematizador de las interrelaciones CTS. En las discusiones de los documentales, se observó una potencialidad para desarrollar diálogos amparados en la perspectiva Freire-CTS, lo que llevó a la elaboración de cuestionamientos, ya que se cree que esta presentación sea un posible auxilio a los profesores que deseen discutir cuestiones relacionadas con la perspectiva Freire-CTS en sus clases. Los audiovisuales problematizadores descriptos se caracterizan como un medio de potenciar la reflexión y el sentido crítico en los sujetos, a fin de analizar y cuestionar la realidad en que están insertados. Este artículo busca presentar los audiovisuales abordados, así como los entendimientos y resultados logrados en el enfoque de los artefactos problematizadores en el proceso de Investigación Temática con los estudiantes de Formación Docente en Física. Las acciones llevadas a cabo (discusión inicial y presentación de los audiovisuales problematizadores) culminaron con el establecimiento del tema generador, energía y CTP, que se analizaron a través de ATD. Emergieron del análisis dos categorías finales tituladas "El enfoque de audiovisuales problematizadores como medio para la discusión de valores sociales" y "Necesidades formativas reveladas a partir de la discusión de documentales problematizadores". El proceso de análisis reveló las potencialidades de los audiovisuales para las discusiones Freire-CTS y la obtención de temas generadores.

Palabras clave: Audiovisuales Problematizadores. Freire-CTS. Formación Inicial de Profesores de Física.

\section{THE USE OF AUDIOVISUALS PROBLEMATIZERS IN THE THEMATIC INVESTIGATION PROCESS AS A MEANS FOR OBTAINING THE GENERATOR THEME}

ABSTRACT: The present article presents an analysis of the Thematic Research process as a result of a didactic intervention with the Science-Technology-Society (STS) interrelationship approach carried out with Physics undergraduate students in a discipline of Physics Teaching practice. The investigation process was based on some actions, such as an initial discussion and presentation of documentaries with a problematizing character of STS interrelationships. In the discussions of documentaries, a potentiality for the realization of dialogues marked by the Freire-STS perspective was noted. The audiovisuals covered are presented, as well as the questions raised. It is believed that this presentation becomes a possible subsidy for teachers who want to discuss issues related to the Freire-STS perspective in their classes. The audiovisual problematizations described are characterized to enhance reflection and critical sense in the subjects, in order to analyze and question the reality in which they are inserted. This article seeks to present the audiovisuals addressed, as well as the understandings and results fabricated in the approach of the problematizing artifacts in the Thematic Research process with the undergraduate students in Physics. The actions carried out (initial discussion and presentation of the problematizing audiovisuals) culminated in the establishment of the generator, energy and STS theme that were analyzed by DTA. From the analysis emerged two final categories entitled "The approach of audiovisual problematizers as a medium for the discussion of social values" and "Formative needs unveiled from the discussion of problematizers documentaries". The analysis process revealed the potential of audiovisuals for Freire-STS discussions and the generation of generating themes. Keywords: Audiovisual Problematizers. Freire-STS. Initial Formation of Physics Teachers. 


\section{ABORDAGEM DE AUDIOVISUAIS NA EDUCAĈ̣̃O: HISTÓRICOE POTENCIALIDADES PARA UMA EDUCAÇÃO TRANSFORMADORA}

O uso dos audiovisuais, na educação, tem início, no Brasil, na década de 1960, quando predominavam os métodos programáticos de ensino. Saviani (1982) argumenta que tal método inspirava-se na crença da racionalidade, eficiência e alimentava-se do pressuposto da neutralidade científica, que possuía grande objetividade na reprodutibilidade dos conteúdos. Subtil e Belloni (2002) argumentam que, naquela época, a eficiência do ensino era decorrente dos métodos programáticos, tecnicistas e tradicionais.

Na segunda metade da década de 1970, surge a tecnologia educacional como uma nova disciplina, baseada em tendências behavioristas, que tinha como objetivo principal obter mão de obra para o mercado de trabalho, partindo, como pressuposto, do uso de meios técnicos para alcançar a produtividade (SUBTIL e BELLONI, 2002). A partir do surgimento da tecnologia educacional como disciplina, os educadores passaram a ser divididos em duas categorias: “(...) os professores e os especialistas pedagogos, cuja função é intervir no processo de ensino no sentido de aumentar sua eficiência" (SUBTIL e BELLONI, 2002, p. 56).

Diante desse contexto, a aproximação entre a área de comunicação e a educação seguia restrita, visto que o ensino apresentava o mesmo caráter técnico e produtivista, seguindo manuais instrucionais, que não objetivava fomentar o despertar crítico e a criatividade nos educandos. As tendências comportamentalistas, que vigoravam naquele período, colaborou para a desvalorização da tecnologia na educação, que segundo Masetto (2006), provocou um descompromisso com a educação, visto que o objetivo central era a transmissão de uma quantidade maior de conteúdos e não a caracterização do tipo de conteúdo transmitido.

No final da década de 1970, temos uma mudança do panorama, em relação ao uso dos audiovisuais na educação. Rosado e Romano (1993) argumentam que houve um aumento na produção desses artefatos, pois devido à superação do regime militar, passou a ser visto como um recurso para disseminar e apoiar as lutas sociais, que ocorriam na época. Naquela época, houve uma mudança de olhar em relação à educação e a alfabetização, fato que está, intrinsecamente, relacionado à inserção de ideias progressistas, nos currículos, como a abordagem CTS. Neste sentido, o objetivo era preconizar a abordagem de conteúdos diversos com significado social, além de motivar o despertar crítico e a necessidade de uma educação, que se estabelecesse fora dos ambientes formais de ensino, ou seja, uma educação para a vida.

A partir desses acontecimentos, passou-se a disseminar pesquisas que abordassem o uso de audiovisuais na educação (CARVALHO, 1996; MORÁN, 1995, ARROIO e GIORDAN, 2006; JESUS, 2008). Alguns autores, como Morán (1995), esclarecem a importância de compreender a essência e a linguagem dos audiovisuais, a fim de possibilitar uma educação mais rica e diversificada. Além disso, é importante estimular o senso crítico nos alunos, mesmo que seja diante das propagandas televisivas com seu marketing implícito, que disseminam uma falsa generosidade para com os telespectadores. Alguns audiovisuais, como os exemplos, que apresentaremos, neste artigo, possibilitarão uma análise crítica da realidade, além de um despertar crítico, acerca de questões corriqueiras, que num primeiro 
olhar, são aparentemente inofensivas. Isto permite, aos educandos, a tomada de decisões responsáveis, diretamente relacionada à generosidade verdadeira, que segundo Freire (1987) são ações que lutam pela dissipação do falso amor, ações realizadas por sujeitos que buscam a transformação do mundo.

Dessa forma, acredita-se que o uso de audiovisuais, com viés transformador, seguindo uma perspectiva progressista, possibilita a construção de uma visão crítica e o desejo de intervir, positivamente, na sociedade, já que tais artefatos possuem potencialidades para a superação de possíveis situações limite. Neste sentido, encaminham-se com os ideais de Freire (1987), que assinala que o homem busca meios de superar as situações limites, indo contra as situações opressoras.

\footnotetext{
"Esta superação, que não existe fora das relações homens-mundo, somente pode verificar- se através da ação dos homens sobre a realidade concreta em que se dão as "situações-limites". Superadas estas, com a transformação da realidade, novas surgirão, provocando outros "atos-limites" dos homens".

Desta forma, o próprio dos homens é estar, como consciência de si e do mundo, em relação de enfrentamento com sua realidade em que, historicamente, se dão as "situações-limites". E este enfrentamento com a realidade para a superação dos obstáculos só pode ser feito historicamente, como historicamente se objetivam as “situações-limites". (FREIRE, 1987, p. 52).
}

Nesse sentido, destaca-se a potencialidade do uso dos audiovisuais, vinculado a uma educação transformadora, que propicie, aos educandos, a construção da autonomia, do senso crítico e da tomada de decisão, mediante as adversidades emergentes. Desta forma, será formado um indivíduo consciente de que tem a capacidade de superar situações-limite futuras, com responsabilidade e generosidade verdadeira.

Freitas, Queirós e Lacerda (2018) investigaram o estado da arte sobre os modos de uso dos artefatos audiovisuais, na Educação em Ciências, nos anos de 2005 a 2014, em periódicos da área de Ensino e constataram que a inserção de audiovisuais ganhou representatividade. No entanto, no Ensino de Ciências ainda é incipiente, e, em sua maioria, apresenta uma característica instrumental. Também foi constatado que há uma carência na abordagem de audiovisuais, com uma perspectiva progressista, como a abordagem Freire-CTS discutida, no presente trabalho.

\section{UM OLHAR SOBRE A ARTICULAC̣ÃO FREIRE-CTS}

O ensino de Ciências, nas escolas, vem apresentando, com o passar do tempo, uma característica internalista. Grande parte das licenciaturas da área de ciências naturais é pautada na racionalidade técnica; em uma análise atual, o ensino de Química, Física e/ou Biologia, mantém-se com as mesmas características do ensino predominante, em décadas passadas (SILVA e OLIVEIRA, 2009), ou seja, valoriza-se o caráter neutro da ciência e o método científico. Este tipo de ensino, dificilmente, contempla temas que apresentem relevância para a sociedade, pois se baseia em um método canônico; no entanto, algumas propostas alternativas (GEHLEN, MALDANER e DELIZOICOV, 2012; SOLINO e GEHLEN, 
2013; SOLINO e GEHLEN, 2016) vêm propondo novos meios de ensino, que apresentam relevância social e estabelecem novos meios de seleção de conteúdos, a partir de uma abordagem temática, para o ensino de Ciências.

Uma das propostas alternativas, para tornar o ensino de Ciências mais relevante socialmente, é a abordagem Freire-CTS, foco de pesquisa de vários autores (AULER e DELIZOICOV, 2006; AULER, DAUMOLIN e FENALTTTI, 2009; ROSO, DAUMOLIN e AULER, 2011; STRIEDER, 2012; ZAUITH e HAYASHI, 2013), cujo cerne de sua apresentação são as potencialidades ao ensino, suas aproximações e distanciamentos. A articulação Freire-CTS baseia-se em três pilares principais, como apresentado por Roso et. al (2015, p. 6-7): "I) currículo estruturado em torno de temas (problemas reais; II) dimensão interdisciplinar no enfrentamento desses temas/ problemas; III) busca da democratização de processos decisórios"; pontos sugestivos de uma educação que ultrapasse a concepção "bancária de educação".

A abordagem temática é adequada para ser utilizada na articulação FreireCTS e outros referenciais progressistas, como Henry Giroux, pois tanto o enfoque CTS, quanto o método de Investigação Temática, proposto por Freire, contribuem para romper com o tradicionalismo do ensino de Ciências, já que partem de uma abordagem temática que apresentam temas reais, que se relacionam com situações cotidianas dos alunos.

(...) enquanto no ensino de base tradicional, a organização do conteúdo tem como elemento central os conceitos (de Física, Química, Biologia e Matemática), nos cursos CTS, a organização da matéria já não se dá com os conceitos no centro, mas sim, através de temas sociais. Isso significa que, os conteúdos dos cursos de disciplinas científicas, via abordagem CTS, necessariamente incluem temas sociais (TEIXEIRA, 2003, p.186).

Ademais, pode-se destacar a contextualização, como um ponto de encontro entre ambas as perspectivas. Neste sentido, Auler (1998, p. 3) explicita que o enfoque CTS "permite compreender problemas relacionados ao contexto do aluno" de modo que "a aprendizagem é "facilitada" porque o conteúdo está situado no contexto de questões familiares e relacionado com experiências extraescolares dos alunos".

Em Freire, a contextualização apresenta-se como eixo central, pois parte do pressuposto da transformação da realidade, e, para que isto ocorra, os sujeitos devem reconhecer temas que estão imersos, os denominados Temas Geradores (FREIRE, 1987). Para Freire, o processo pedagógico inicia-se com a busca dos temas, que partem dos sujeitos, com vistas à transformação da realidade; assim, na articulação Freire-CTS, um dos objetivos é tornar os sujeitos mais críticos, pois possibilitaria uma análise crítica da realidade, a fim de potencializar o desejo de transformação social, visando um mundo mais justo e igualitário.

O presente artigo apresenta parte dos resultados de uma dissertação de mestrado (Freitas, 2018), que teve como um dos objetivos estudar o uso de audiovisuais problematizadores no processo de Investigação Temática e as ações desenvolvidas pautaram-se na abordagem CTS. Assim, buscou-se compreender "quais as potencialidades do uso de audiovisuais problematizadores no processo de Investigação temática com professores de física em Formação Inicial"? 
As discussões dos audiovisuais centraram-se em temas de relevância social: como o descarte inadequado de materiais; consumismo exacerbado; influência da tecnologia sobre a sociedade; a relação entre ser humano e meio ambiente; questões relacionadas à obsolescência programada; uso desgovernado de fontes energéticas; poder exercido pela política na sociedade e em outros meios.

Das discussões, surgiram reflexões acerca do encaminhamento formativo dos licenciandos e inquietações como: "o que é ser um bom professor"? As ações realizadas possibilitaram reflexões e viabilizaram a obtenção do tema gerador, ou seja, a temática surgiu, a partir de discussões de temas sociais que causavam inquietações. O percurso metodológico utilizado na pesquisa e os resultados tecidos são explicitados nos próximos itens.

\section{PERCURSO METODOLÓGICO}

Esta pesquisa baseia-se em uma análise do uso de documentários, com abordagens problematizadoras vinculadas ao processo de Investigação Temática (DELIZOICOV e ANGOTTI, 1990; DELIZOICOV, ANGOTTI e PERNAMBUCO, 2002) a fim de obter o tema gerador. A pesquisa foi realizada no curso de licenciatura em Física, da Universidade Federal de Mato Grosso do SulUFMS, com sete alunos, na disciplina intitulada "Práticas de Ensino de Física IV", cujo foco é a discussão das inter-relações CTS, no Ensino de Física. Os alunos eram caracterizados, por alguns professores, como passivos e acríticos, e, desta forma, as ações realizadas buscaram compreender as questões que os inquietavam, a fim de entender estas limitações. ${ }^{1}$

As etapas da pesquisa ancoraram-se no processo de Investigação temática, proposto por Freire (1987), composto por cinco etapas: 1) levantamento preliminar: reconhecimento local da comunidade; 2) Codificação: realização de uma análise e escolha das contradições vivenciadas pelos envolvidos; 3) Descodificação: é realizada a validação dessas situações e a sintetização em temas geradores; 4) Redução temática: seleção de conceitos científicos para dar respaldo ao tema e o planejamento de ensino; 5) Desenvolvimento em sala de aula: implementação de atividades.

O processo de sequência temática embasou-se na proposta metodológica de Torres et. al., (2008), que consiste em articular a ATD (MORAES, 2003; 2005; MORAES e GALIAZZI, 2007), a metodologia de análise de dados da presente pesquisa, com o processo de Investigação temática (FREIRE, 1987). A respeito da articulação, os autores explicitam:

(...) a vinculação de uma "estratégia" de estruturação de programas escolares a uma metodologia de análise de dados pode "organizar o currículo escolar de forma a romper com a hegemonia conteudista e bancária que desconsidera os problemas sociais na realidade dos estudantes (TORRES et. al., 2008, p. 2).

Nesse sentido, considera-se adequado o uso desta articulação nos estudos, que propusemos para encaminhar a pesquisa ao referencial teórico utilizado. A partir desta metodologia, pôde-se levantar o contexto vivenciado pelos sujeitos de pesquisa, bem como identificar possíveis contradições emergentes. Estes 
movimentos possibilitaram, após a obtenção do tema gerador, a construção de uma sequência temática que contribuiu para a desmistificação de crenças errôneas sobre questões, que envolvem CT e a possibilidade de uma formação transformadora e emancipatória, a partir do Tema Gerador. Desta forma, Torres et. al (2008) propõem a aproximação entre ATD e a investigação temática, como demonstrado na síntese da Figura 1:

Figura 1. Aproximação entre ATD e Investigação temática

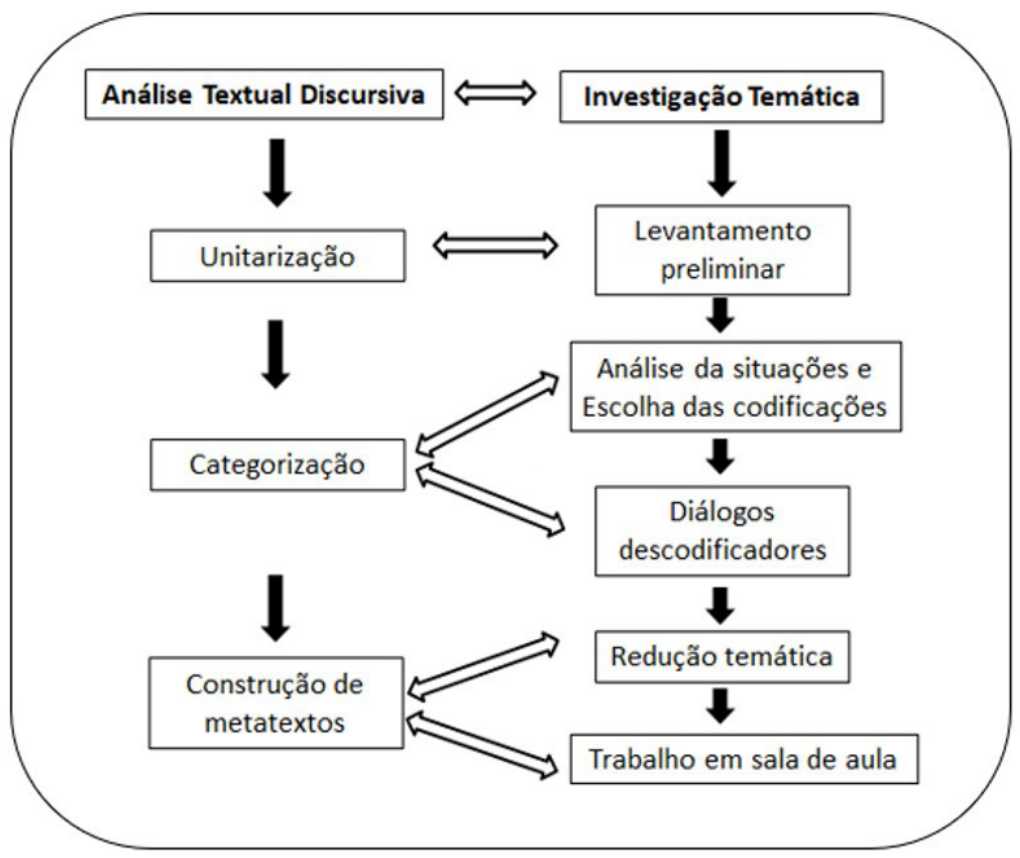

Fonte: Elaborado pelos autores.

Torres et. al., (2008) articulam a aproximação ATD e Investigação Temática em três pontos: 1) Levantamento Preliminar à unitarização; 2) Escolhas das Situações Significativas e os Diálogos Descodificadores à categorização e 3) A Redução Temática e o Desenvolvimento em Sala de Aula da comunicação/metatexto.

Sobre o último processo de articulação, os autores argumentam que é necessário desenvolver o senso crítico, pois se trata da etapa em que os educadores desenvolverão recursos pedagógicos, que devem apresentar um viés crítico, na busca por uma educação transformadora. Compreende-se que a aproximação entre a ATD e o processo de Investigação temática caracteriza-se como uma base para criar metodologias e estratégias que propiciem a constituição de um currículo em uma perspectiva crítico-progressista de educação. As atividades desenvolvidas, em sala de aula, ancoradas no processo de investigação temática, seguem descritas no próximo item. 


\subsection{ATIVIDADES DESENVOLVIDAS PARA OBTENC̣ÃO DO TEMA GERADOR}

Em um primeiro momento do círculo de investigação temática para o levantamento preliminar, aplicou-se um questionário, ${ }^{2}$ a fim de ter acesso às compreensões dos licenciandos sobre concepções relacionadas à CTS, que também auxiliou na obtenção do tema gerador. Ademais, a metodologia do levantamento preliminar foi adaptada, de modo que o grupo participante atuasse nas decisões de todas as etapas, a fim de conhecer melhor o método.

Em um segundo momento, realizamos alguns questionamentos para entender o universo em que esses licenciandos estavam inseridos. $\mathrm{Na}$ segunda etapa do processo de investigação temática, codificação, foram apresentados alguns documentários com caráter problematizador, a fim de propiciar discussões sobre questões discutidas com a temática CTS, de forma implícita, pois neste momento ainda não se buscou definir e discutir, explicitamente, os pressupostos CTS. Após a efetivação das atividades, foi realizada uma discussão sobre as ações realizadas, a fim de se obter o tema gerador, que viesse dos alunos, pois a partir de debates e reflexões realizadas, no decorrer das aulas, deveriam, em comunhão, optar por um tema a ser trabalhado na disciplina.

Em seguida, foi realizada a etapa de descodificação, que trata da discussão das ações que foram objeto de codificação. Na etapa de redução temática, as discussões giraram em torno de algumas temáticas como: o que é ser um bom professor, reflexões sobre o encaminhamento formativo dos licenciandos, questões relacionadas a valores sociais, ética, economia, política e ambiente, o que de acordo, com nossas interpretações, deram origem ao tema gerador e a abordagem CTS, que serão descritos na análise dos resultados e discussão. Ainda sobre a etapa de redução temática, cabe ressaltar que, seguindo os fundamentos freireanos, deve ser realizada por uma equipe multidisciplinar ou, neste caso, pela pesquisadora. No entanto, como o objetivo pedagógico da disciplina ofertada na Formação Inicial de Professores tem um enfoque CTS, sob um viés crítico-transformador, achamos necessária a participação dos licenciandos em tal processo.

Uma problemática que norteou as discussões para o tema gerador foi o pagamento de taxa mínima de energia. A partir de discussões políticas e econômicas, que estão diretamente relacionadas a esta questão, emergiu, também, como tema gerador, a questão energética, tratada com maior profundidade na discussão e análise dos resultados. O quadro abaixo expõe uma síntese das atividades realizadas para atingir o tema gerador, bem como seus objetivos. 
Quadro 1. Síntese do planejamento metodológico.

\begin{tabular}{|c|c|c|c|}
\hline $\begin{array}{l}\text { Passos da } \\
\text { Investigação } \\
\text { temática }\end{array}$ & Atividades & Objetivos & Duração \\
\hline \multirow{2}{*}{$\begin{array}{l}\text { Levantamento } \\
\text { Preliminar }\end{array}$} & $\begin{array}{l}\text { Questionário } \\
\text { inicial }\end{array}$ & $\begin{array}{l}\text { Analisar de forma implícita, as } \\
\text { compreensões dos licenciandos } \\
\text { sobre questões relacionadas à } \\
\text { CTS. }\end{array}$ & 1 hora- aula. \\
\hline & Discussão Inicial & $\begin{array}{l}\text { Compreender a situação, em que } \\
\text { os sujeitos de pesquisa estão } \\
\text { inseridos. }\end{array}$ & 1 hora-aula. \\
\hline Codificação & $\begin{array}{l}\text { Apresentação } \\
\text { de audiovisuais } \\
\text { com abordagens } \\
\text { problematizadoras }\end{array}$ & $\begin{array}{l}\text { Discutir, de forma implícita, } \\
\text { questões relacionadas à } \\
\text { abordagem Freire-CTS, como } \\
\text { superação da cultura do silêncio } \\
\text { e do modelo de decisões } \\
\text { tecnocráticas. }\end{array}$ & 3 horas- aula. \\
\hline Descodificação & $\begin{array}{l}\text { Aula expositiva } \\
\text { dialógica, pautada } \\
\text { em discussões dos } \\
\text { audiovisuais. }\end{array}$ & $\begin{array}{l}\text { Discutir questões CTS, } \\
\text { implicitamente relacionadas aos } \\
\text { audiovisuais; História das coisas, } \\
\text { zumbis ao celular e obsolescência } \\
\text { programada. }\end{array}$ & 4 horas- aula. \\
\hline $\begin{array}{l}\text { Redução } \\
\text { temática }\end{array}$ & $\begin{array}{l}\text { Discussão para } \\
\text { obtenção do tema } \\
\text { gerador. }\end{array}$ & $\begin{array}{l}\text { Possibilitar aos educandos, um } \\
\text { momento de reflexão e discussão } \\
\text { acerca das ações realizadas, } \\
\text { objetivando atingir o tema } \\
\text { gerador. }\end{array}$ & 2 horas-aula. \\
\hline
\end{tabular}

Fonte: Elaborado pelos autores.

\subsection{EXEMPLOS DE AUDIOVISUAIS PROBLEMATIZADORES E SUAS POSSIBILIDADES PARA DISCUSSÕES DA ARTICULAÇÃO FREIRE-CTS.}

As potencialidades do uso de documentários problematizadores para potencializar discussões CTS já foram sinalizadas por Barbosa e Bazzo (2013). Os autores afirmam que estes artefatos, caracterizam-se como recursos para elevação do pensamento crítico dos alunos e podem ser utilizados nos diversos níveis educacionais. Corroboramos com os autores, visto que para realizar uma análise dos audiovisuais é necessário um olhar crítico para as questões éticas, políticas e econômicas; e, para realizar tais reflexões, é necessário construir uma postura cidadã entre os sujeitos, a fim de que possam analisar o universo em que estão inseridos, bem como a tríade CTS.

A seguir são apresentadas as sinopses dos audiovisuais problematizadores ${ }^{3}$ abordados na disciplina de Prática de ensino de Física IV, bem como os questionamentos utilizados para dar início às discussões, a partir da etapa de codificação. 


\subsubsection{História das coisas}

O filme, The Story of Stuff (2007), de Annie Leonard, é bastante utilizado no campo educacional, quando se objetiva possibilitar discussões/sensibilizações sobre questões ambientais. Este documentário demonstra claramente como funciona o sistema da cadeia produtiva do consumo, apresentando o processo desde a extração da matéria-prima, confecção do produto, marketing publicitário e venda, a facilidade de compra e falsa ideia de necessidade de obtenção, até o momento de descarte do produto, em lixões ou a incineração.

O documentário propicia discussões Freire-CTS/CTSA, e, dependendo do nível de criticidade dos participantes envolvidos, tais diálogos podem propiciar a desalienação, bem como chamar atenção/conscientizar sobre o consumismo exacerbado e o modo de vida das pessoas, no século XXI (BARBOSA e BAZZO, 2013). Para os alunos da disciplina de Prática de Ensino de Física IV, as discussões foram centradas nas seguintes questões: Qual a necessidade do ser humano em buscar novos bens? Você acredita que o ato de comprar aumenta a desigualdade social? Que fator "invisível" é este que vem transformando o padrão de vida das pessoas? Você já se perguntou de onde vem e para onde vão os objetos que compramos? A seta de consumo que aparece durante o documentário, pode ser problematizada? Por que não conseguimos fugir do sistema mercantilista implantado? De que forma a educação pode mudar o cenário apresentado no documentário?

Tais questionamentos apresentaram certa complexidade, no sentido de que aborda questões que vão além de problemas ambientais e econômicos, pois envolvem adversidades que estão presentes no cotidiano dos sujeitos. Desta forma, exige uma criticidade para que sejam discutidos, bem como a necessidade de permitir-se retirar o manto de alienação que nos assola.

\subsubsection{Zumbis ao celular}

O material audiovisual, de autor desconhecido, demonstra a realidade de uma sociedade escravizada e alienada pelo uso excessivo da tecnologia. $\mathrm{O}$ vídeo ganhou certa visibilidade nas redes sociais e apresenta como foco central reflexões que norteiam o resgate de valores, como o diálogo e a socialização entre as pessoas.

Pretende-se por meio desse vídeo, abrir espaço para discussão de questões como a natureza da tecnologia, o efeito da tecnologia sobre a ciência e sobre a sociedade e discussões que permitam a desalienação sobre questões relacionadas à ideias de determinismo tecnológico. Para atingir os objetivos, foram realizados alguns questionamentos aos licenciandos: No que a sociedade vem se tornando? Estamos perdendo a noção do mundo real para o mundo abstrato? Como impedir que nos tornemos apenas Zumbis ambulantes, inseridos num mundo imaginário? Qual o papel da tecnologia na sociedade? O que o seu celular representa para você? Você conseguiria permanecer por um período, sem este objeto?

Tais indagações desvelaram discussões sobre questões relativas à CTS, bem como reflexões acerca do desenvolvimento da Ciência e Tecnologia, no século XX, suas potencialidades e limitações. 


\subsubsection{Obsolescência Programada}

Trata-se de um documentário espanhol, lançado em 2010, nos Estados Unidos, intitulado The Light Bulb Conspiracy, dirigido por Cosima Dannoritzer. O documentário inicia com a apresentação de um contraste na indústria das lâmpadas, já que, no ano de 1920, cada lâmpada durava em média 2500 horas e, nos dias atuais, duram em média 1000 horas; esta diferença aconteceu quando os fabricantes se deram conta de que "deveriam" diminuir a durabilidade para aumentar o consumo. Neste viés, o filme aborda como tema central, a manipulação industrial na durabilidade de alguns produtos, com o objetivo de estimular o consumo de versões mais atuais.

Foram realizados alguns questionamentos com o intuito de possibilitar diálogos críticos entre os alunos, tais como: Em algum momento algum objeto quebrou e você verificou que teria maior lucro em comprar um novo, do que consertar? Você acredita que a obsolescência programada traz consequências para o meio ambiente? Quais seriam? Esta ação tem relação com as problemáticas do lixo e energia que até hoje nos assola? Estamos estafando o planeta com o constante descarte energético e de produtos. Mas, por que tomamos tais atitudes?

Tais questões possibilitaram discussões Freire-CTS/CTSA e diálogos sobre o poder exercido pelo mercado e a subestimação da força dos movimentos sociais. O documentário permite que o sujeito manifeste suas reflexões que possibilitam desvelar uma realidade antes escondida, e, mais que isso, possibilita uma leitura crítica do mundo, como defendido por Freire (1987).

\section{RESULTADOS E DISCUSSÕES}

Nas próximas seções são apresentadas as sínteses dos metatextos, que expõem as compreensões e interpretações resultantes das discussões dos documentários com os licenciandos. O primeiro metatexto, apresenta discussões relacionadas a valores sociais, o segundo, elucida algumas questões formativas que emergiram durante o processo de obtenção do tema gerador.

\subsection{A ABORDAGEM DE AUDIOVISUAIS PROBLEMATIZADORES COMO MEIO PARA DISCUSSÃO DE VALORES SOCIAIS}

O desenvolvimento de uma prática educacional, pautada na reflexão crítica acerca das causas, implicações e efeitos causados pelos hábitos de consumo exacerbado, vem ganhando cada vez mais visibilidade. Parte de pressupostos discutidos pela abordagem CTS/CTSA, buscam chamar atenção, dentre várias outras vertentes, para uma educação que desperte para o consumo responsável.

A7U6: É como as pessoas que tem um celular que custa $\mathrm{R} \$ 4.000,00$ e não tem dinheiro para colocar crédito. Eu acho que isso acontece porque a pessoa quer ser aceita na sociedade. As pessoas pensam que por você ter o último iPhone você é rico e está sendo aceito. 
A discussão sobre os documentários propiciou uma visão sobre consumismo, que tornou possível analisar a realidade complexa, em que vivemos. As questões apontadas pelo licenciando traz, em suas raízes, questões culturais e históricas, como a competição, a falsa idealização de que valores sociais constituemse numa base consumista e na superficialidade.

O trecho demonstra o quanto os sujeitos encontram-se limitados em sua criticidade e com a ideologia de que a aceitação social é contingência de bens materiais. Estes pontos alertam-nos para a realização de uma análise crítica sobre o sistema autoritário e ditatorial que nos permeia, e também, a indagarmos: A quem estamos servindo? Como mudar este cenário? Acreditamos que "A educação deve ajudar o homem brasileiro a inserir-se criticamente no processo histórico e libertar-se pela conscientização, da síndrome do ter e da escravidão do consumismo". (FREIRE, 1987). Na mesma vertente, o trecho A2U16 traz a visão de um licenciando sobre a influência da tecnologia sobre a sociedade.

A2U16: eu acho que a tecnologia era pra auxiliar, mas está formatando a sociedade. Por exemplo, as pessoas hoje em dia perderam o contato, a gente vê um grupo de pessoas todas com o celular na mão, ao invés de estarem conversando. As pessoas perderam o dom de conversar, as vezes entram em um site de relacionamentos para encontrar um namorado sendo que tem várias pessoas ao seu redor.

$\mathrm{O}$ argumento exposto demonstra que o licenciando realiza uma análise crítica do uso deturpado da tecnologia, apresentando algumas questões abordadas pela perspectiva CTS, como o determinismo tecnológico, por exemplo. Além disso, apresenta o conhecimento de que o produto da tecnologia deveria ser utilizado para auxiliar a sociedade, ou seja, a sociedade deveria ter uma participação ativa em sua elaboração, a fim de usufruir os resultados com sabedoria. No entanto, pelo olhar do aluno, a sociedade vem sendo objeto de formatação.

Ao serem questionados se a educação pode mudar essa paisagem, ou seja, se a educação poderia mudar o estilo de vida das pessoas, tornando-as mais críticas, e como isso poderia acontecer, a maioria dos licenciandos não soube responder, como possibilitar o desenvolvimento de tais valores.

Acredita-se que a educação pode mudar essa realidade, a partir do desenvolvimento da curiosidade crítica, pois a especulação pode fazer com que os sujeitos se defendam de irracionalidades e de verdades impostas. Freire (2014) elucida que, as irracionalidades são produzidas pelo excesso de racionalidade desta era altamente tecnologizada, portanto, é extremamente necessário despertar o senso e análise críticas dos sujeitos, para que, "[...] de um lado, não diviniza a tecnologia, mas, de outro não a diaboliza. De quem olha ou mesmo a espreita de forma criticamente curiosa." (FREIRE, 2014, p.34).

\subsection{NECESSIDADES FORMATIVAS DESVELADAS, A PARTIR DA DISCUSSÃO DE DOCUMENTÁRIOS PROBLEMATIZADORES}

A Formação docente tornou-se objeto de estudo e causa inquietações nos pesquisadores, uma vez que gera controvérsias e reflexões sobre seu 
encaminhamento. Quando se fala em uma fundamentação progressista na FP, perspectiva embasadora deste trabalho, a discussão estreita-se em favor da construção da autonomia dos educandos e educadores. A busca pela autonomia docente junto à ideia de profissionalidade gerou várias pesquisas e discursos pedagógicos (FREIRE, 2014; SANCHES, 1995; MONTEIRO, 2006; GUERRA e VEIGA, 2007; CONTRERAS, 2002), já que se compreende que o desenvolvimento desta autonomia diminui as restrições no ensino e do envolvimento hierárquico dos professores e estabelece pouca participação em processos decisórios, como a criação de políticas educacionais e seu fazer educacional.

As discussões realizadas, a partir dos documentários, remeteram-nos à necessidade de aprofundar reflexões, em atividades posteriores, sobre questões que abordam a autonomia docente. Quando se perguntou aos licenciandos se fariam uso dos documentários em aulas de Física no Ensino Médio, a maioria argumentou que não, pois não enxergava uma aplicação em conteúdos de Física; outros disseram que o professor não dispõe de tempo, no decorrer do ano letivo, como pode ser analisado no fragmento A1U34:

A1U34: Mas o professor não tem tempo de passar vídeo e cumprir a ementa, é muita coisa. A gente concorda que dá para discutir muita coisa importante, mas e o tempo?

O trecho acima explicita a constituição da ideologia do profissionalismo abordado por Contreras (2002), que, com o passar do tempo, o professor passou a interpretar que as orientações estabelecidas por agentes externos deveriam ser incorporadas ao seu trabalho. Esta ação, de acordo com o autor, diminuiu a participação dos professores em processos formativos decisórios, pois se baseia na proletarização do trabalho docente.

A autonomia não é construída de forma isolada, necessita de trabalho coletivo, uma busca por solucionar problemas educativos e, principalmente, relaciona-se ao estabelecimento de uma autocrítica das ações docentes, bem como uma crítica da realidade e dos problemas que emergem do fazer educacional. As discussões formativas propiciadas pela reflexão dos documentários desvelaram um olhar para a limitação da criticidade dos licenciandos. Como pode ser vislumbrado no trecho A1U26, abaixo:

A1U26: a gente fala sobre conhecimento científico, sobre a pessoa ser crítica, mas se eu chegar na sala de aula e falar qualquer coisa, os alunos vão acreditar no que eu estou falando, porque o professor é visto como "sabe tudo". Até aqui mesmo (universidade), acreditamos em tudo que os professores falam. Tínhamos uma professora que passava tudo errado no quadro, e perguntava: Está correto? Todo mundo falava que sim! Porque foi ela quem passou. Depois é que ela discutia e falava o porquê não estava certo. Então, nem a gente tem essa criticidade que dirá o aluno da escola (grifo nosso).

O licenciando explicita a carência do despertar crítico em seu processo formativo e o trecho acima sinaliza a urgência de uma reflexão crítica sobre a formação de professores, pois se compreende que o ensino deve ser concebido 
como uma atividade de crítica, com um compromisso transformador (GIROUX, 1987; 1997). É necessário repassar a ideia de que os professores não exercem apenas o papel de cuidar da aprendizagem dos alunos, mas devem exercer um papel de formação de valores, tanto individuais quanto sociais; pois, isto despertará, em seus alunos, os princípios de igualdade, ética e criticidade, a fim de analisar as adversidades do mundo com uma lente de transformação e emancipação.

Em busca de respostas para a passividade e acriticidade dos licenciandos nas aulas de disciplinas formativas, e, em outras pesquisas nas quais foram sujeitos de análise, a maioria das respostas girou em torno da explicitação exposta no fragmento abaixo:

A1U3: As outras pessoas que vieram fazer pesquisa com a gente davam um tema, e falavam que era aquele tema que seria trabalhado. Muitas vezes a gente nem se interessava pelo tema, então a gente não estava nem aí.

Estudos pautados na perspectiva freireana apontam a importância da organização curricular, na educação formal baseada em Temas Geradores (LINDEMANN, 2010; GEHLEN, MALDANER e DELIZOICOV, 2012), obtidos por meio do processo de Investigação Temática (FREIRE, 1987). O objetivo desta perspectiva é abordar temas que apresentam significância para os alunos, ou então, selecionados, pelo próprio professor, com características semelhantes ao que Freire (1987) denominou de Temas Dobradiça.

Quando um tema real, parte de situações que os alunos vivenciam, eles se sentem instigados a buscar novos conhecimentos que ainda não detém, a fim de buscar compreendê-lo, a fim de transformar a sua realidade. Para a obtenção do tema gerador, foram realizadas discussões com os educandos, a fim de que sinalizassem, em suas falas, elementos que desvelassem o tema; assim, os alunos enfatizaram, em diversos momentos da discussão, que a temática deveria abranger uma abordagem CTS.

A5U4: Eu acho que a questão de energia é uma boa então... fontes renováveis, por exemplo, discutir a aplicação de painéis solares, o que ele envolve, discutir a eficiência, se é uma boa ou não. Acho que esse é um tema CTS.

A6U6: O que a gente poderia falar de CTS no tema energia? Se a gente falar sobre os painéis solares como o A5 disse. A gente poderia discutir a tecnologia das indústrias que constroem, a física que explica a transformação de energia, e ver o que as pessoas pensam. Se compensa ou não usar as fontes renováveis.

O problema é o elemento principal que estrutura a programação curricular, que se consolida mediante a obtenção e desenvolvimento do Tema Gerador (SOLINO e GEHLEN, 2013). Segundo as autoras, o tema traz à tona, a compreensão dos sujeitos acerca da realidade em que se inserem: o problema, portanto, é o principal elemento estruturante da programação curricular, que se consolida mediante a obtenção e desenvolvimento do Tema Gerador. Este tema permite a compreensão, pelos sujeitos, do nível de consciência sobre as problemáticas envolvidas, para que possam buscar meios para superá-las. Sobre isso, Delizoicov (1982): 
O tema gerador gerará um conteúdo programático a ser estudado e debatido, não só como um conteúdo insípido e através do qual se pretende iniciar o aluno ao raciocínio científico; não um conteúdo determinado a partir da ordenação dos livros textos e dos programas oficiais, mas como $\mathrm{um}$ dos instrumentos que tornam possível ao aluno uma compreensão do seu meio natural e social (DELIZOICOV, 1982, p. 11, grifo do autor).

As discussões geraram elementos que nortearam os estudantes a refletirem sobre questões que os envolviam diretamente, como o pagamento da taxa mínima de energia e a importância da inserção de fontes energéticas renováveis. O fragmento A6U8 abaixo apresenta a curiosidade do estudante acerca do pagamento da taxa mínima, quando argumenta: eu queria saber mais sobre isso:

A6U8: Eu estou aqui pensando... no que o A5 falou, será que a gente tem que pagar uma taxa mínima mesmo usando as placas solares em casa? Eu queria saber sobre isso.

Em resposta, o aluno A3 argumenta:

A3U7: Eu acho que tem que pagar uma taxa, é como a professora disse a gente paga a taxa mínima para manter o funcionamento... Distribuição de energia essas coisas. Com certeza, a gente vai pagar alguma coisa. Mas é muito injusto.

A6U9: com certeza é injusto! Eu não estou usando energia, por que eu tenho que pagar uma taxa? $\mathrm{Na}$ minha casa, por exemplo, a taxa mínima custa $\mathrm{R} \$ 70,00$ (setenta reais).

Em meio às discussões sobre o pagamento da taxa mínima de energia e a necessidade de inserção de fontes renováveis de energia no estado de Mato Grosso do Sul, emergiu o tema energia a ser trabalhado, sob uma abordagem CTS. No entanto, após as discussões e explicitações sobre reconhecimento das potencialidades dos temas, os alunos expuseram uma preocupação em relação à aplicação de trabalhar o tema energia sob uma perspectiva CTS, no Ensino Médio:

A5U9: Acho que vai ficar legal, acho que a gente não precisa falar só de energia mecânica, potencial essas coisas... Pode falar também sobre as fontes renováveis de energia, energia solar... E descobrir essas coisas da taxa mínima de energia. Porque é muito injusto.

A6U12: Vai ficar legal, mas e se a gente tiver que aplicar isso no Ensino Médio, como a gente faz? Acho que não tem isso no referencial. E eu não posso deixar de passar, sei lá... Energia potencial, por exemplo, que tá lá no referencial, pra passar isso.

O fragmento apresentado A6U12 demonstra que o aluno apresenta a compreensão de que a abordagem temática inserida em aulas de Física apresenta potencialidades, mas, no entanto, camufla-se em meio às compreensões tradicionalistas e reproducionistas.

A partir do fragmento exposto, é importante refletir sobre qual papel deve ser exercido pelo professor dentro da escola, pois se pode reproduzir a hegemonia dominante e os objetivos do currículo oculto (GIROUX, 1997). Neste viés, o 
autor elucida algumas ameaças, que permeiam o professor:

Uma das maiores ameaças aos professores existentes e futuros é o desenvolvimento crescente de ideologias instrumentalistas que enfatizam uma abordagem tecnocrática para a preparação dos professores e também para a pedagogia de sala de aula. No cerne da atual ênfase nos fatores instrumentais e pragmáticos da vida escolar colocam-se diversas suposições pedagógicas importantes. Elas incluem: o apelo pela separação de concepção e execução; a padronização do conhecimento escolar com o interesse de administrá-lo e controlá-lo; e a desvalorização do trabalho crítico e intelectual de professores e estudantes pela primazia de considerações práticas (GIROUX, 1997, p. 158).

Nesses termos, a função do professor torna-se reproduzir tarefas e programas curriculares definidos por outros, que convivem em outros âmbitos, diferentes do qual o currículo é desenvolvido. Nesse contexto, o professor não desenvolve e nem se apropria, de forma crítica, de currículos que atendam aos objetivos pedagógicos específicos. Para superar este obstáculo, Giroux (1997) sugere que a formação docente siga um parâmetro crítico-transformador, onde os professores: atuem como Intelectuais transformadores, desenvolvendo o pensamento crítico sobre a própria prática docente dentro de sala de aula, dentro da escola e nos seus extramuros e neguem a utilização de práticas predefinidas, que fundamentam educação em uma perspectiva de racionalidade instrumental. Assim, é possível que professores e alunos se unam em um discurso de desenvolvimento de ações e criem uma esfera contrapública democrática (GIROUX, 1997).

\section{CONSIDERACְÕES FINAIS}

O uso dos audiovisuais problematizadores no processo de Investigação temática mostrou-se um instrumento com potencialidade para discussão FreireCTS, além de possibilitar reflexões críticas sobre questões de relevância social, como o consumismo, degradação ambiental, influência das grandes mídias, dentre outras. Ademais, configurou-se como ferramenta principal para a obtenção dos temas geradores, energia e abordagens CTS.

A discussão de temas sociopolíticos é algo que se encontra distante dos ambientes de ensino, já que há uma escassez de trabalhos, na busca pela democratização, em debates, sejam eles políticos, econômicos ou científicos (GIROUX, 1987). Tal configuração necessita de mudança, e vimos que, o uso de materiais audiovisuais vinculados à perspectiva CTS, em sala de aula, foi um meio para possibilitar tais discussões. No entanto, Moran (1995) e Gomes (2008) defendem que é necessário estabelecer reflexões de acordo com o perfil dos estudantes. Neste sentido, destacamos a potencialidade do uso dos audiovisuais no processo de Investigação temática, visto que no primeiro movimento da investigação, levantamento preliminar, tem-se a permissividade de conhecer os sujeitos, bem como o ambiente no qual estão inseridos.

A análise das discussões e reflexões dos audiovisuais problematizadores, realizadas via ATD, propiciaram-nos compreender as concepções éticas e sociais dos licenciandos, bem como algumas questões formativas emergentes. Pôde- 
se compreender que os licenciandos ainda seguem imersos em uma concepção curricular tradicional e conteudista, como pode ser verificado no argumento A1U34, onde o licenciando explicita a potencialidade do uso dos audiovisuais, porém afirma que o professor não possui tempo para abordá-los. Tais denotações são discutidas e reforçaram-nos a intenção de realizar intervenções pautadas nos temas geradores emergentes (energia e abordagens CTS), a fim de possibilitar e, quiçá, motivar, nos licenciandos, o desejo e a busca por um ensino valoroso e igualitário.

Os temas e problemáticas que surgiram pelo processo de Investigação temática, como a questão do pagamento da taxa mínima de energia, serviram como arcabouço para a realização das atividades, em sala de aula. Ademais, as necessidades formativas sinalizadas pelos licenciandos, como a acriticidade, tradicionalismo e concepção disciplinar de currículo, potencializaram a necessidade em realizar intervenções pautadas, numa perspectiva progressista e transformadora.

\section{REFERÊNCIAS}

AULER, D. Movimento ciência-tecnologia-sociedade (CTS): modalidades, problemas e perspectivas em sua implementação no ensino de física. VI Atas do Encontro Nacional de Pesquisa em Ensino de Física, Florianópolis: SBF, 1998.

AULER, D.; DELIZOICOV, D. Educação CTS: articulação entre pressupostos do educador Paulo Freire e referenciais ligados ao movimento CTS. Seminário Ibérico CTS no ensino das ciências: las relaciones CTS en la Educación Científica, v. 4, p. 1-7, 2006.

AULER, D.; DALMOLIN, A. M. T.; FENALTI, V. S. Abordagem temática: natureza dos temas em Freire e no enfoque CTS. Alexandria: revista de educação em ciência e tecnologia, v. 2, n. 1, p. 67-84, 2009.

ARROIO, A.; GIORDAN, M. O vídeo educativo: aspectos da organização do ensino. Química nova na escola, v. 24, n. 1, p. 8-11, 2006.

BARBOSA, L. C, A.; BAZZO, W. A. O uso de documentários para o debate ciência-tecnologiasociedade (CTS) em sala de aula. Ensaio Pesquisa em Educação em Ciências, v. 15, n. 3, p. 149-161, 2013.

CARVALHO, A. M. P. O uso de vídeos na tomada de dados: pesquisando o desenvolvimento do ensino em sala de aula. Pro-posições, v. 7, n. 1, p. 5-13, 1996.

CONTRERAS, J. A autonomia de professores. Cortez, 2002.

DELIZOICOV, D. Concepção problematizadora do ensino de ciências na educação formal: relato e análise de uma prática educacional na Guiné Bissau. 1982. 227 f. Dissertação (Mestrado) Universidade de São Paulo, São Paulo, 1982.

DELIZOICOV, D.; ANGOTTI, J. A. Metodologia do ensino de ciências. 1990.

DELIZOICOV, D; ANGOTTI, J. A.; PERNAMBUCO M. M. Ensino de Ciências: fundamentos e métodos. Cortez Editora, 2002.

FREIRE, P. Pedagogia do Oprimido. Rio de Janeiro: Paz e Terra, 1987. 
FREIRE, P. Pedagogia da autonomia: saberes necessários à prática docente. $49^{\mathrm{a}}$ ed. São Paulo: Paz e Terra, 2014.

FREITAS, V. M.; QUEIRÓS, W. P.; LACERDA, N. O. Audiovisuais como temática de pesquisa em periódicos brasileiros de educação em ciências. Caderno Brasileiro de Ensino de Física, v. 35, n. 2, p. 592-633, 2018.

FREITAS, W. P. S. O enfoque CTS na formação inicial de professores: compreensões e obstáculos para uma ação docente crítico-transformadora. Dissertação de mestrado. Campo Grande: UFMS/PPEC, 2018.

GEHLEN, S.T.; MALDANER, O. A.; DELIZOICOV, D. Momentos pedagógicos e as etapas da situação de estudo: complementaridades e contribuições para a educação em ciências. Ciência $\boldsymbol{\&}$ Educação, v. 18, n. 1, p. 1-22, 2012.

GIROUX, H. Escola crítica e política cultural. Cortez; Autores Associados, 1987.

GIROUX, H. Os professores como intelectuais: rumo a uma pedagogia crítica da sociedade. Porto Alegre: Artmed, 1997.

GOMES, L. F. Vídeos Didáticos: uma proposta de critérios para análise. Revista Travessias, Cascavel, v. 2, n. 3, 2008.

GUERRA, T.; VEIGA, F. Autonomia profissional dos professores. Revista da Universidade dos Açores: Arquipélago - Ciências da Educação, n. 8, p.39-58, 2007.

JESUS, R. M. V. de. Escola e documentário: uma relação antiga. Revista HISTEDBR On-line, Campinas, n.32, p. 233-242, 2008.

LINDEMANN, R. H. Ensino de Química em Escolas do Campo com Proposta Agroecológica: Contribuições a partir da Perspectiva Freireana de Educação. Tese de Doutorado. Florianópolis: UFSC/PPGECT, 2010.

MASETTO. M. T. Mediação pedagógica e o uso da tecnologia. In: MORAN, J. M.; MASETTO, M. T.; BEHRENS, M. A. Novas tecnologias e mediação pedagógica. Ed. 12, Novas tecnologias e mediação pedagógica. $8^{a}$ ed. Campinas, SP: Papirus, 2006. p.133-173.

MORAES, R. Uma tempestade de luz: a compreensão possibilitada pela análise textual discursiva. Ciência \& Educação, v. 9, n. 2, p. 191-211, 2003.

MORAES, R. Mergulhos discursivos: análise textual qualitativa entendida como processo integrado de aprender, comunicar e interferir em discursos. In: GALIAZZI, M. C.; FREITAS, J. V. (org.) Metodologias emergentes de pesquisa em educação ambiental. Ijuí: UNIJUÍ, 2005, p. 85- 114.

MORAES, R. GALIAZZI, M. C. Análise Textual Discursiva. Ijuí: UNIJUÍ, 2007.

MONTEIRO, M. Um estudo da autonomia docente no contexto do ensino de ciências nas séries iniciais do ensino fundamental. Bauru, 2006. Tese (Doutorado em Educação para a Ciência). Universidade Estadual Paulista, Faculdade de Ciências.

MORAN, J. M. O vídeo na sala de aula. Comunicação \& Educação, n. 2, p. 27-35, 1995.

ROSADO, E. M. S.; ROMANO, M. C. J. S. O Vídeo no Campo da Educação. Unijuí, 1993, 80p. 
ROSO, C. C.; DALMOLIN, A. M. T.; AULER, D. Práticas educativas balizadas por Freire e CTS. Encontro Nacional de Pesquisa em Educação em Ciências, v. 8, 2011.

ROSO, C. C. SANTOS, R. A. ROSA, S. E. AULER, D. Currículo temático fundamentado em FreireCTS: engajamento de professores de física em formação inicial. Ensaio Pesquisa em Educação em Ciências, v. 17, n. 2, p. 372-389, 2015.

SANCHES, M. A autonomia dos professores como valor profissional. Revista de Educação, v.5, n. 1, p.42-63, 1995.

SAVIANI, D. Escola e Democracia, São Paulo. 1982.

SILVA, C. S.; OLIVEIRA, L. A. A. Formação Inicial de professores de química: Formação específica e pedagógica. In: NARDI, R. Ensino de Ciências e Matemática: Temas sobre a formação de professores. São Paulo: UNESP, 2009.

SOLINO, A. P.; GEHLEN, S. T. Abordagem temática freireana e o ensino de ciências por investigação: possíveis relações epistemológicas e pedagógicas. Investigações em Ensino de Ciências, v. 19, n. 1, p. 141-162, 2016.

SOLINO, A.P.; GEHLEN, S. T. A contextualização na Abordagem Temática Freireana e no Ensino de Ciências por Investigação. Encontro Nacional de Pesquisa em Educação em Ciências, v. 9, p. 1-8, 2013.

STRIEDER, R. B. Abordagens CTS na educação científica no Brasil: sentidos e perspectivas. 2012. Tese de Doutorado. Universidade de São Paulo.

SUBTIL, M. J.; BELLONI, M. L. Dos audiovisuais à multimídia: análise histórica das diferentes dimensões de uso dos audiovisuais na escola. A formação na sociedade do espetáculo. São Paulo: Loyola, p. 47-72, 2002.

TEIXEIRA, P. A educação científica sob a perspectiva da pedagogia histórico-crítica e do movimento CTS no ensino de ciências. Ciência \& Educação, vol. 9, núm. 2, 2003.

TORRES, J. R.; GEHLEN, S. T.; MUENCHEN, C.; GONÇALVES, F.P; LINDEMANN, R. H. GONÇALVES, FJ.F. Ressignificação curricular: contribuições da Investigação Temática e da Análise Textual Discursiva. Revista Brasileira de Pesquisa em Ensino de Ciências, v. 8, n. 2, 2008.

ZAUITH, G.; HAYASHI, M. C. P. I. A influência de Paulo Freire no Ensino de Ciências e na Educação CTS: uma análise bibliométrica. Revista HISTEDBR On-line, v. 13, n. 49, p. 267-293, 2013.

\section{NOTAS}

1 Isso será mais bem abordado (seção de resultados) no metatexto intitulado "Necessidades formativas desveladas a partir da discussão de documentários”.

2 O presente artigo não apresenta os resultados obtidos pelo questionário inicial. São apresentados os resultados obtidos pela discussão inicial, apresentação de audiovisuais, aula expositiva e busca/ obtenção do tema gerador.

3 A história das coisas. Disponível em:

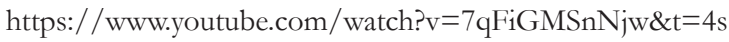

Zumbis ao celular. Disponível em: 
https://www.youtube.com/watch?v=a4GmuTBsyPI

Obsolescência programada. Disponível em:

https://www.youtube.com/watch?v $=$ H7EUyuNNaCU\&t $=8 \mathrm{~s}$

Submetido em 06/08/2019

Aprovado em 09/06/2020

\section{Contato:}

Cidade Universitária - Universidade Federal de Mato Grosso do Sul

Programa de Pós-Graduação em Ensino de Ciências

Instituto de Física - Bloco 5, Setor 1 - Campo Grande

CEP 79.070-900 - MS - Brasil

\section{ERRATA}

DOI: http://dx.doi.org/10.1590/1983-21172020210130

Elocator: e1488422

No artigo: WÉLICA PATRÍCIA SOUZA DE FREITAS. WELLINGTON PEREIRA DE QUEIRÓS. O USO DE AUDIOVISUAIS PROBLEMATIZADORES NO PROCESSO DE INVESTIGAÇÃO TEMÁTICA COMO MEIO PARA OBTENCCÃO DO TEMA GERADOR. Ens. Pesqui. Educ. Ciênc. (Belo Horizonte), Belo Horizonte , v. 22, e14884, 2020. Disponível em <https://www.scielo.br/scielo.php?script=sci_ arttext\&pid $=\$$ S1983-21172020000100320\&tlng=pt $>$. Acesso em 16 set. 2020. Epub Set 04, 2020. http://dx.doi.org/10.1590/21172020210121

Em autores do artigo,

Onde se lia:

Wélica Patrícia de Souza Freitas.

Leia-se:

Wélica Patrícia Souza de Freitas. 